\title{
Building Simulation will be published bi-monthly from Vol. 7
}

\author{
Xudong Yang ( $\square)$ \\ Editor-in-Chief \\ Department of Building Science, School of Architecture, Tsinghua University, Beijing 100084, China
}

() Tsinghua University Press and Springer-Verlag Berlin Heidelberg 2013

This issue marks the beginning of the Building Simulation's 7 th year of service to the building simulation community. The journal is undergoing rapid growth in many ways. One indicator of its growth is the increasing number of high quality submissions we receive every week. This reflects the increasing number of research activities in this field and the trust of many distinguished authors to publish in our journal.

To meet this increasing demand from both our readers and authors, the publishers and editors have decided to change the journal publication frequency from quarterly to bi-monthly, effective Issue 1, Vol. 7 (2014). By making this change, we expect to double the number of research papers published each year, reaching 60-70 articles each year.

Let me assure you that the quality control and timeliness of the manuscript review process will not be affected by this change. We will further tighten the quality control by imposing higher standards in accepting papers. To ensure timely review during our two-round double-blind review process, we have set a target of 6 months from a paper's initial submission to publication. If authors respond quickly to revisions and proof-reading, as many currently do, papers can be published online within 3-4 months of the initial submission!

With all these changes, I am requesting the help of our scientific community and readers. If you are an author or invited reviewer, please continue to act quickly in revising or reviewing. To our readers, please check with the library at your home institution to ensure that Building Simulation is available. Every year, each publisher provides a list of journals to libraries that they can subscribe to as a package. We hope that Building Simulation is one of the journals on the subscription list provided by our publishers: Springer or Tsinghua University Press. If you have any special requests for our editorial office, please do not hesitate to let us know.

Last but not least, I thank our authors, reviewers, readers, editorial board members and publishers for helping to make the journal a success. We look forward to your continued readership and article submission to Building Simulation. 